\title{
DEVELOPMENT OF WIRELESS POWER TRANSFER SYSTEM USING RESONANCE PRINCIPLE WITH SECURITY FEATURES
}

\author{
Chandrasekharan Nataraj ${ }^{*}$, Sheroz Khan $^{2}$, Mohamed Hadi Habaebi ${ }^{2}$, \\ asan Gani Abdul MUthalif ${ }^{3}$ and Ravi Lakshmanan ${ }^{1}$

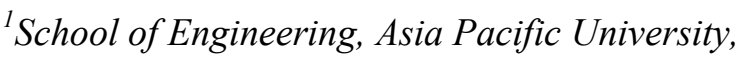 \\ 57000, Kuala Lumpur, Malaysia. \\ ${ }^{2}$ Department of Electrical and Computer Engineering, \\ ${ }^{3}$ Department of Mechatronics Engineering, \\ International Islamic University Malaysia, \\ Jalan Gombak, 53100 Kuala Lumpur, Malaysia. \\ *Corresponding author: chander@apu.edu.my \\ (Received: 17 $7^{\text {th }}$ March 2016; Accepted: $13^{\text {th }}$ Nov. 2017; Published on-line: $1^{\text {st }}$ Dec. 2017)
}

\begin{abstract}
This research describes a resonance principle based low power Wireless Power Transfer (WPT) system. The reflective impedance model is derived to evaluate the resonance coupling between coils. Additionally, a Cockroft-Walton voltage boosting circuit is incorporated to boost up the received voltage to the appropriate level, instead of using traditional conditioning circuits. The prototype model, operating at $130 \mathrm{kHz}$, is demonstrated experimentally and analysed graphically to validate the performance of the designed circuit. For an overall span of $100 \mathrm{~mm}$ coil separation distance, a maximum efficiency of $60 \%$ with no load and $36 \%$ with loaded system, is observed at a distance of $55 \mathrm{~mm}$ with approximate (e.g., manual) axial orientation of coils. It can be supported widely for portable electronic products and biomedical devices. As an added contribution, the WPT circuit was enabled by a password security feature using an Arduino microcontroller.
\end{abstract}

ABSTRAK: Kajian ini menerangkan sistem tanpa wayar (wireless) berkuasa rendah berasaskan prinsip resonans pemindahan kuasa (Power Transfer (WPT)). Model pantulan rintangan telah dihuraikan bagi menilai resonans antara dua gegelung litar. Selain itu, litar peningkatan voltan Cockroft Walton turut digunakan untuk meningkatkan input voltan pada tahap sesuai, tanpa mengguna pakai litar tradisional. Prototaip model pada operasi $130 \mathrm{kHz}$, telah diuji secara eksperimen dan dianalisa secara grafik untuk menilai prestasi litar yang dicipta. Bagi span keseluruhan $100 \mathrm{~mm}$ jarak pemisahan gegelung, kecekapan maksimum 60\% tanpa beban dan 36\% dengan beban sistem telah diperhatikan pada jarak $55 \mathrm{~mm}$ berdasarkan anggaran (secara manual) pada orientasi paksi gegelung. Kajian ini sesuai digunakan secara meluas pada produk mobil elektronik dan peranti bioperubatan. Sebagai sumbangan tambahan, litar WPT telah diaktifkan dengan ciri keselamatan kata laluan mengguna pakai sistem pengawal mikro Arduino.

KEYWORDS: wireless power transfer; resonant frequency; refelective impedance; microcontroller

\section{INTRODUCTION}

Wireless Power Transfer (WPT) consists of energy transfer from any appropriate source to an energy consuming device without the use of wires or conducting material. Wireless power transmission has received special attention recently for the 
implementation of low-cost and low-power batteryless operated sensors. The development of portable devices in the digital world has increased the demand of battery-less gadgets. Devices are usually powered through cables, or any other conductive material, from wall outlets or other power sources such as battery cells. These existing methods may not be feasible choices in certain applications while battery use eventually requires replacement of exhausted batteries. Batteryless technology is a favourable method for powering electronic gadgets without the use of wires or cables. WPT technology is emerging as an essential companion to the handheld portable products of the very near future. WPT is realized through an electric field called a capacitive coupling or a magnetic field inductive coupling. The magnetic field coupling based wireless power transfer was historically conceptualized in 1891 by Nikolas Tesla [1]. However, its practical application has only recently appeared to satisfy the needs of emerging field applications and the devices of the portable digital world.

The inductively coupled resonance WPT has numerous benefits, such as being simple in construction, omnidirectional, non-radiative, effective for midrange power transfer, and losing minimum power [2]. In theory, inductive and capacitive coupling modes are popular methods to transfer power wirelessly. The capacitive coupling has many limitations and could be used for very limited applications as compared to the inductive coupling [3]. The inductive coupling technique has been used in many low power applications [4]. There are three modes that are commonly used for WPT, such as inductive coupling for short range, resonant coupling for mid-range, and electromagnetic coupling for long range [5]. The coils are resonated at a resonant frequency, maximizing power transfer to devices at locations by few centimeters away.

As per the application requirement, the geometry of the inductor coils can be diverse and the shapes can also vary, from circular, to rectangular or square $[6,7]$. The use of the resonant technique in WPT to charge the devices at close proximity is a low cost feasible technique $[8,9]$. At resonance, two coupled circuits will oscillate at a particular frequency referred to as resonance frequency through an impedance matching technique [10]. A resonant based WPT system integrated with the digital controller can make up an innovative approach. Earlier studies focused on addressing the primary objective of increasing power efficiency through shortening coil separation distance [11]. Existing systems do not contain any provisions to control the power transfer between transmitter and receiver coils.

In real time applications, a WPT system without control units will supply power to the remotely connected load at times when power transfer is not needed [12]. These kind of systems are not sustainable and lead to the unnecessary power wastage and increases the demand for increased power supply. This can be avoided when any kind of controlling mechanism is provided in the transmitter circuit for controlled transfer of power between source and load coils. The usage of microcontrollers is a well-known technique to facilitate the controlling prospects. The system, comprising of both a WPT and a digital controller, is referred to as an integrated system. This integrated system also serves many purposes including cost reduction, improved protection, and centralised monitoring [13]. Hence, a password-based digital controller was combined with WPT, making it a more attractive technique for biometric authentication embedded with distinctive biological features [14].

This paper is organized as follows: Section II describes the theory of reflective impedance involved in the WPT. The complete design details of WPT with password 
protection are explored in Section III. Consequently, the findings of the experiments and its validations are presented in Section IV. Finally, the conclusion is drawn in Section V.

\section{CIRCUIT THEORY BASED WPT MODEL USING REFLECTIVE IMPEDANCE}

Figure 1 depicts the electrical equivalent circuit for the WPT system and it can be represented in matrix form by assuming voltages and currents in r.m.s values,

$$
\left[\begin{array}{cc}
R_{s S}+j\left(\omega L_{S C}+1 / \omega C_{1}\right) & -j \omega M \\
-j \omega M & R_{L L}+j\left(\omega L_{L C}-1 / \omega C_{2}\right)
\end{array}\right]\left[\begin{array}{c}
I_{S} \\
I_{L}
\end{array}\right]=\left[\begin{array}{c}
V_{S} \\
0
\end{array}\right]
$$

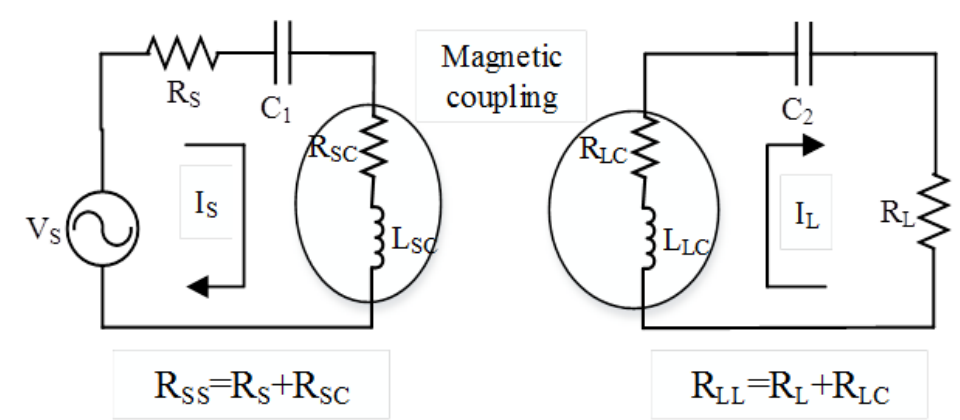

Fig. 1: Electrical equivalent circuit.

The source and load coil inductances and resistances are represented as $L_{S C}, L_{L C}, R_{S C}$ and $R_{L C}$. The value of $R_{S}, R_{L}, C_{1}$ and $C_{2}$ represents source resistance, load resistance, and loading capacitors of source and load circuits, respectively. When two coils placed in the critical coupling mode, the coupling factor $\mathrm{k}$ can be represented as,

$$
k=\frac{1}{\sqrt{Q_{S} Q_{L}}} \text {. }
$$

Where $Q_{S}=\frac{\omega L_{S C}}{R_{S S}}$ and $Q_{L}=\frac{\omega L_{L C}}{R_{L L}}$ are the $Q$ factors of source and load coils. Under nonmutual induction, oscillating angular frequencies of source and load coil are defined as,

$$
\omega_{S}=\frac{1}{\sqrt{L_{S C} C_{1}}} \text { and } \omega_{L}=\frac{1}{\sqrt{L_{L C} C_{21}}} .
$$

Capacitors $C_{1}$ and $C_{2}$ are added to each side and tuned appropriately. Both coils will oscillate at an angular resonance frequency $\omega=1 / \sqrt{L_{\text {Coil }} C}$. Then, maximum power transfer takes place from source to load coil in the critical coupling mode. At the resonant condition, conventional Figure of Merit $(U)$ of the complete circuit is written as,

$$
U=k \sqrt{Q_{S} Q_{L}}
$$


Hence, intensity of magnetic field established in the source coil shall be improved by the value of the $Q$ factors. These values are very appropriate to significantly increase the efficiency and maximum achievable efficiency can be represented as,

$$
\eta_{o p t}=\frac{U}{\left(1+\sqrt{1+U^{2}}\right)^{2}}
$$

Rather than this conventional method, Circuit Theory (CT) based analysis is more appealing because of characteristics of straightforward mutual inductance calculation [9].

Figure 2 illustrates the simplified reflected impedance model for the electric equivalent circuit of WPT shown in Fig. 1. Let us consider $R_{r e f}, Z_{s}$ and $M_{S C}$ are representing the reflected impedance from load to source loop, source side total impedance, and mutual inductance, respectively. Under resonance state, the impedance reflected from load to source coil is referred as reflective impedance.

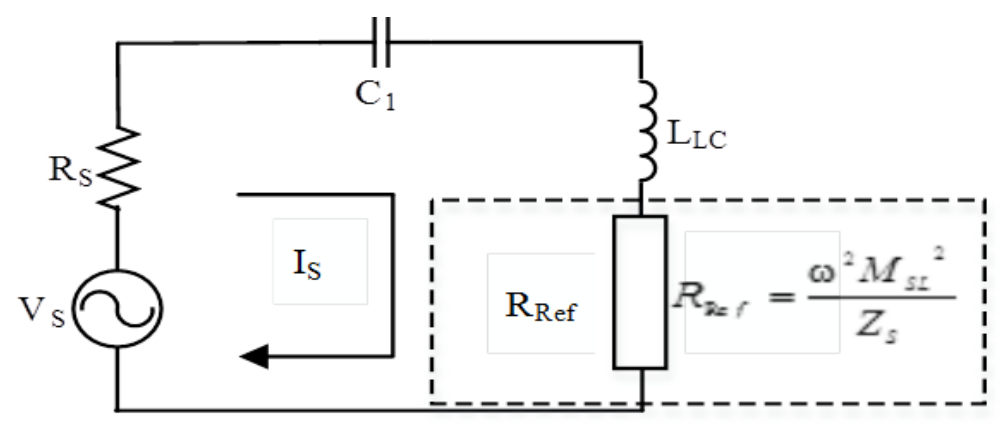

Load coil refelction to source

Fig. 2: Simplified reflective impedance model.

$$
\begin{aligned}
& Z_{r e f}=\frac{\omega^{2} M_{S L}^{2}}{R_{L C}+R_{L}} \\
& \eta=\frac{\omega^{2} M_{S L}^{2}}{\left(R_{L C}+R_{L}\right)\left[\omega^{2} M_{S L}^{2}+\left(R_{S C}+R_{S}\right)\left(R_{L C}+R_{L}\right)\right]} \\
& P_{L}=\frac{\omega^{2} M_{S L}^{2} V_{S}^{2} R_{L}}{\left[\omega^{2} M_{S L}^{2}+\left(R_{S C}+R_{S}\right)\left(R_{L C}+R_{L}\right)\right]^{2}}
\end{aligned}
$$

Equations (7) and (8) represent the conditions for maximizing the power transfer efficiency and hence power received at the load with respect to $M_{S L}$ and $R_{L}$. With the above equations, and transfer power related with reflected impedance can be drawn easily.

$$
\begin{aligned}
& \eta_{\text {max }}=\sqrt{\frac{\omega^{2} M_{S L}{ }^{2} R_{L C}}{R_{S C}+R_{S}}} \\
& P_{L \text { Max }}=\frac{\omega^{2} M_{S L}{ }^{2}}{R_{S C}+R_{S}}+R_{L C}
\end{aligned}
$$


Equations (9) and (10) represent the optimized equations for achieving maximum efficiency and power.

Figure 3(a) shows the measurement of the coupling factor as a function of coil separation distance, with an applied input voltage of $5 \mathrm{~V}$. The system is tested with three different coil sizes of $20 \mathrm{~mm}, 25 \mathrm{~mm}$, and $30 \mathrm{~mm}$. It is observed that the coupling factor (k) achieves almost unity for the $30 \mathrm{~mm}$ sized coil for less than $10 \mathrm{~cm}$ of coil separation distance while it achieves a 0.2 coupling factor when the coil separation distance reaches $70 \mathrm{~cm}$. In general, the inference made is that the coupling factor $(k)$ decreases as the coil separation distance is increased. Similarly, Fig. 3(b) shows the measurement of output voltage as a function of coupling factor. The output voltage is measured by varying the coupling factor from 0.1 to 1 in both simulation and experimental analysis. The coupling factor is calculated through the formula $k=\frac{Q_{L}}{Q_{S}}$, where $Q_{S}$ and $Q_{L}$ are the quality factor of source and load coils respectively. Hence, the coupling factor is inversely proportional to the distance of coil separation between source and load coils. In other words, increasing the separation distance reduces the coupling factor, and vice versa.

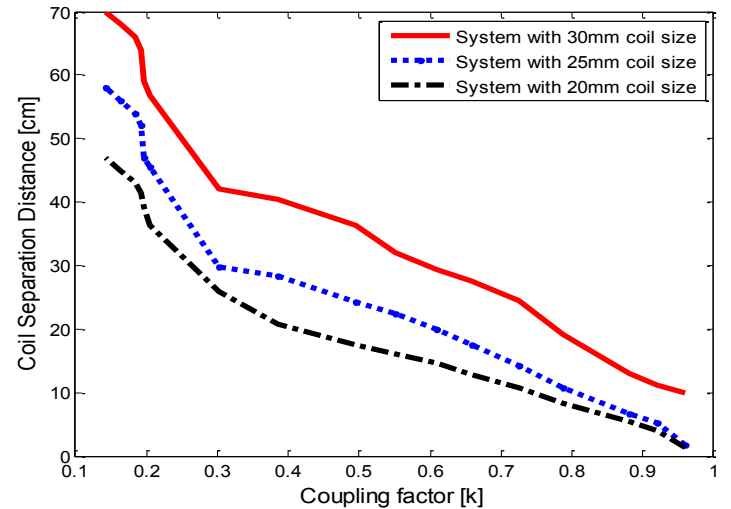

(a)

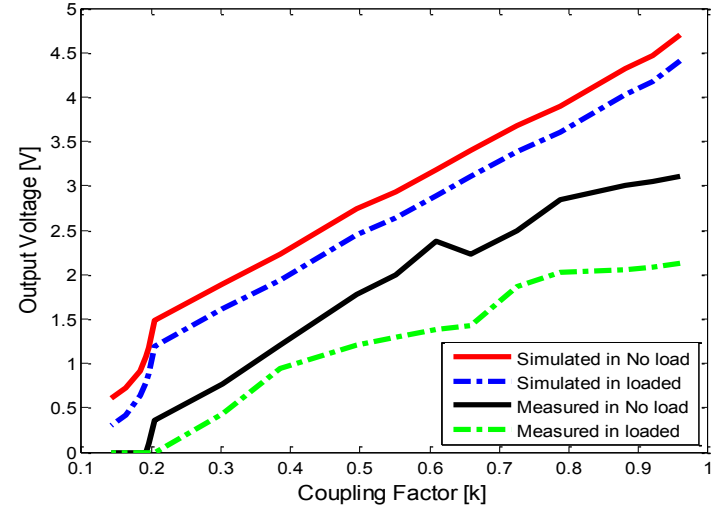

(b)

Fig. 3: (a) Measurement of coupling factor as a function of coil separation distance with different coil sizes (b) Simulated and experimental measurement of output voltage as a function of coupling factor for no load and load conditions.

Subsequently, it can be observed that the output voltage gradually increases as coupling factor is increased, for both the simulated and measured results. However, the simulated output voltage increases rapidly, reaching a maximum of $4.5 \mathrm{~V}$ at the resonant coupling factor $k=0.95$, while the measured output voltage produces $3 \mathrm{~V}$ only for the same resonant coupling factor under no load condition. This is due to several factors such as the component tolerance levels, accuracy of winding of coupled coils, quality factor of coils and, most importantly, the accuracy of coil orientation, all of which add an element of uncertainty to the obtained results. Furthermore, the simulated output voltage increases gradually, reaching a maximum peak of $4 \mathrm{~V}$ at resonant coupling factor $k=0.95$, while the measured output voltage produces $2 \mathrm{~V}$ only at the same resonant coupling factor under loaded condition. Thus, only $60 \%$ and $40 \%$ of the output voltage has been achieved experimentally as compared to simulation, both under no load and loaded conditions. This is due to fact that the experimental results exhibit uncertainties in the measurements as compared to the simulation results. 
However, this could be further improved through the use of more reliable components with less tolerance levels and using motorized setting for accurate coil orientation. Furthermore, it is observed that the optimum peak voltage of $2.25 \mathrm{~V}$ and $1.25 \mathrm{~V}$ occurs at the resonant condition with a coupling factor of 0.6 under no load and loaded condition. This is equivalent to $25 \mathrm{~cm}$ of separation distance for a $30 \mathrm{~mm}$ sized coil. Hence, it can be concluded that the system with the coupled inductive coils provides an optimum power transfer efficiency under the resonance coupled condition.

\section{DESIGN OF WPT SYSTEM WITH PASSSWORD PROTECTION}
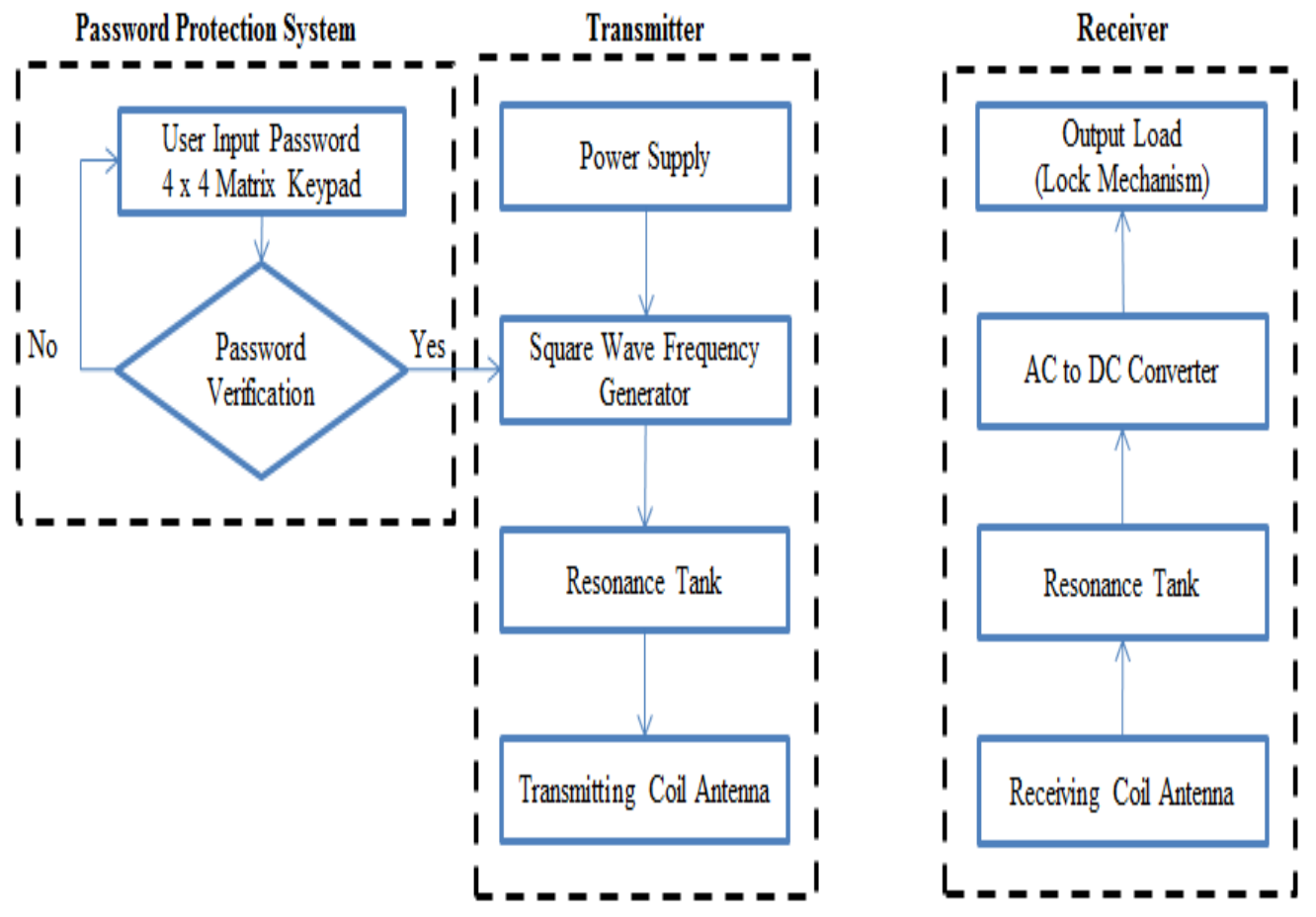

Fig. 4: Hardware block diagram of a wireless power system with password security.

A simple and cost-effective integrated wireless power transfer system embedded with password authentication features is shown in Fig. 4. The whole system is resonated at a frequency of $130 \mathrm{kHz}$ and a separate password security digital module is developed to control the frequency of generator circuit. The password protection system provides a degree of user control, in which only an authorised user can activate the system. Upon entry of the password, the transmitter module is activated and the transmitter coils get coupled to receiver coil at resonance. In resonance mode, both transmitter and receiver circuits are tuned into a common frequency, thus maximizing power transfer. The voltage across the receiver coil is rectified as dc and will be used as a appropriate power for the target IC as load. The IC 555-based square wave generator in Fig. 4 is designed and operated at resonant frequency. The DC input supply is converted into AC pulses to excite the transmitter coil for generating the required magnetic field. The receiver coil, under the influence of the magnetic field, then induces a voltage, and is hence able to deliver AC voltage across it, making power ready to be harvested. The harvested voltage is passed to the conditioning circuit and rectifier, converting it back to DC voltage for use by the load circuit.

The hardware circuit of the frequency generator shown in Fig. 5 comprises of a 555 timer, MOSFET switch and two NPN transistors. As mentioned earlier, the square wave 
output generated from 555 timer is applied to the MOSFET switch for conditioning and stabilizing purposes. It means that the stable alternating pulses are generated to trigger $\mathrm{ON}$ and OFF NPN transistors thus exciting the transmitter coil in a pre-determined sequential manner. The purpose of two transistors is to provide the good driving capability for developing appropriate voltage across the transmitter tank circuit. Pin.3 of the IC 555 provides the functionality of an external trigger.

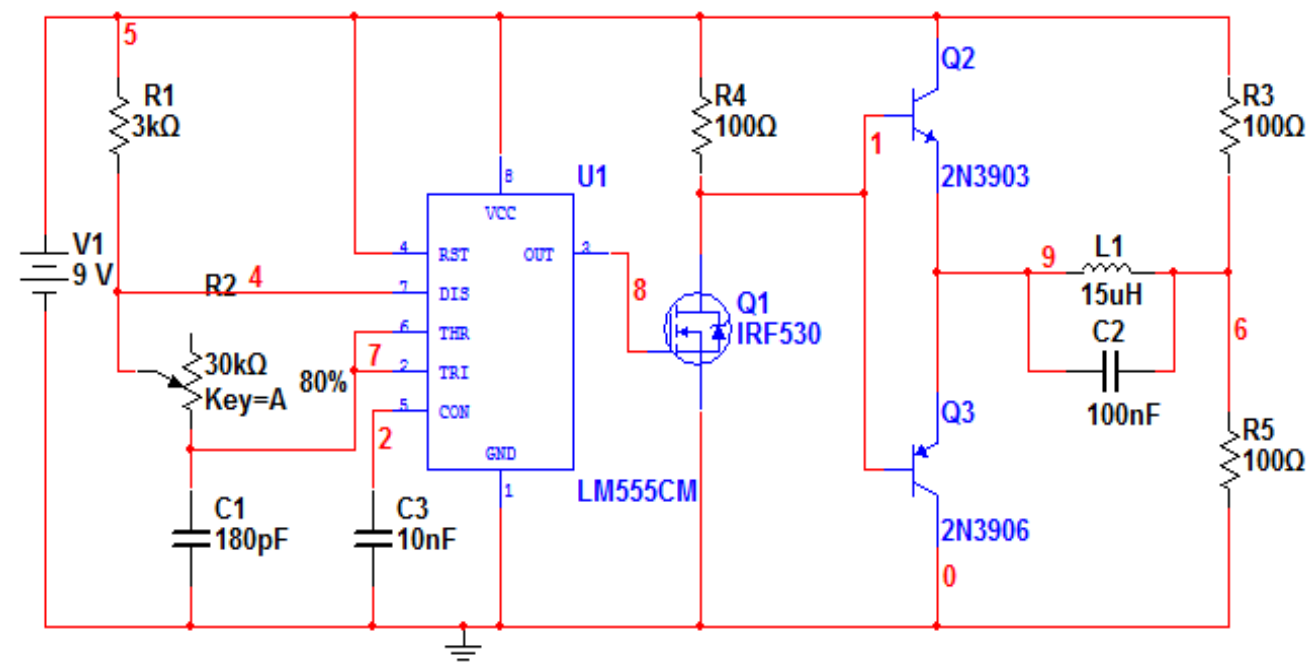

Fig. 5: Resonant frequency generator circuit.

In order to enable the successful power transfer, the coil inductance deciding the performance of the system, is determined using Wheeler's formula [15]:

$$
L=\frac{31.6 a^{2} n^{2}}{6 a+9 l+10(b-a)}
$$

Where, $\mathrm{L}=$ self-inductance in $\mu H ; a=$ inner radius of coil in meter; $b=$ outer radius of coil in meter; $l=$ length of coil in meter; and $n=$ total number of turns. The inductance of the coil inductor is calculated with the parameters listed in Table 1 is,

$$
L=\frac{31.6(0.066)^{2}(11)^{2}}{6(0.066)+9(0.005)+10(0.07-0.066)}=15.177 \mu H .
$$

Table 1: Coil parameters in the coil designs.

\begin{tabular}{cccc}
\hline $\begin{array}{c}\text { Self-Inductance } \\
(\boldsymbol{\mu H})\end{array}$ & $\begin{array}{c}\text { Inner radius } \\
(\mathbf{m})\end{array}$ & $\begin{array}{c}\text { Outer radius } \\
(\mathbf{m})\end{array}$ & $\begin{array}{c}\text { Length } \\
(\mathbf{m})\end{array}$ \\
\hline 15.177 & 0.031 & 0.035 & 0.006 \\
\hline
\end{tabular}

In addition, a special Cockroft-Walton (CW) voltage boosting converter is adopted in this design to convert harvested AC voltage across the receiver coil into desired DC voltage, by boosting the received output voltage. This circuit is constructed using voltage multipliers along with conditioning capacitors and uni-directional diodes as of Fig. 6. 


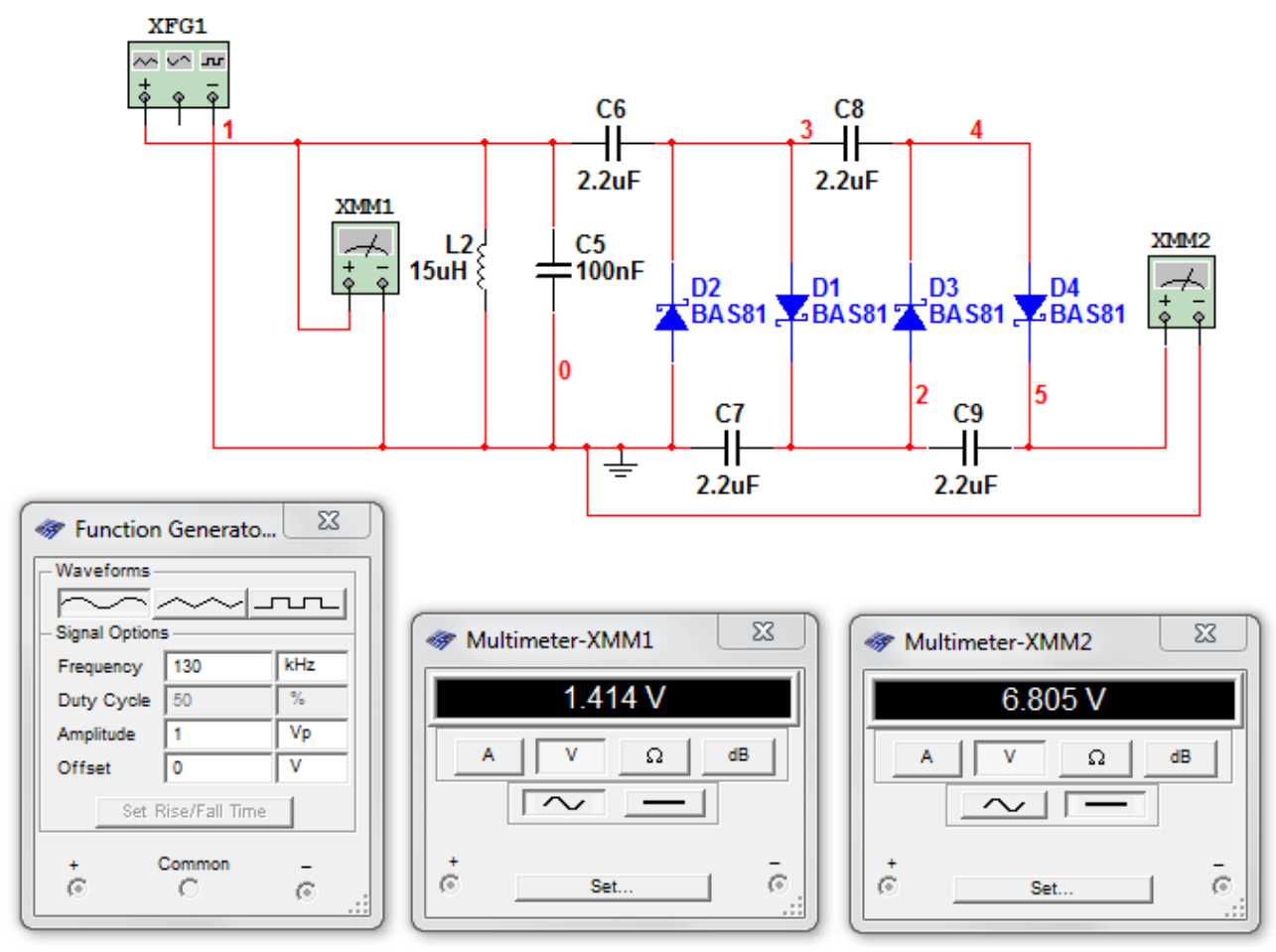

Fig. 6: Simulation diagram and the measurements of Cockroft Walton voltage boosting circuit.

An experimental setup of an Arduino microcontroller-based WPT system integrated with password security functionality is shown in Fig. 7. The resonant frequency for the transmitter module is authenticated by a password security system using the Arduino processor. The trigger control signal generated by the microcontroller is connected to pin.3 of the IC 555 timer-based oscillator circuit. The oscillator will generate the resonant frequency when the password is entered through the keypad. Then, the power is harvested by the receiver coil under resonant coupling mode through the microcontroller which initiates the control signal to trigger up the transmitter module and thereby achieve wireless power transfer. In this work, a new feature of authentication technique based on a microcontroller is adopted. The developed system has a significant feature of password protection integrated with the wireless power transfer system.

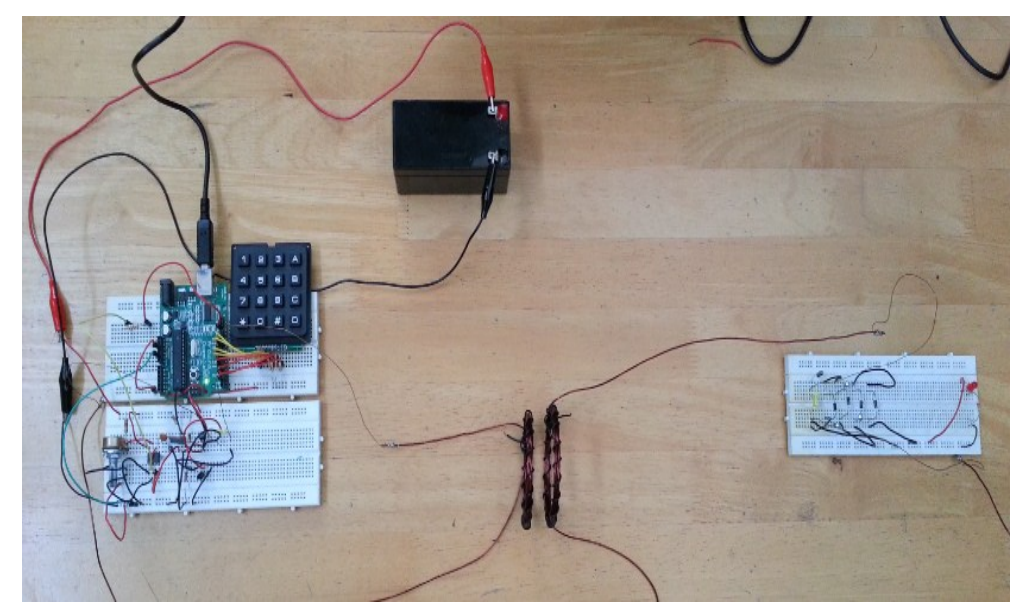

Fig. 7: Experimental setup of password security based WPT system. 


\section{RESULTS AND DISCUSSION}

The developed lab test bed WPT system is evaluated and analysed using two experimental set-ups. Both experiments are conducted using the coil of diameter of $7 \mathrm{~cm}$ with 0.5 initial air gap by applying a $5 \mathrm{~V}$ input voltage. The efficiency of the designed system in terms of voltage is measured using two parameters: coil separation distance in axial and radial orientations. It is experimented through the setup of two same sized stationary coils oriented in parallel planes to each other.

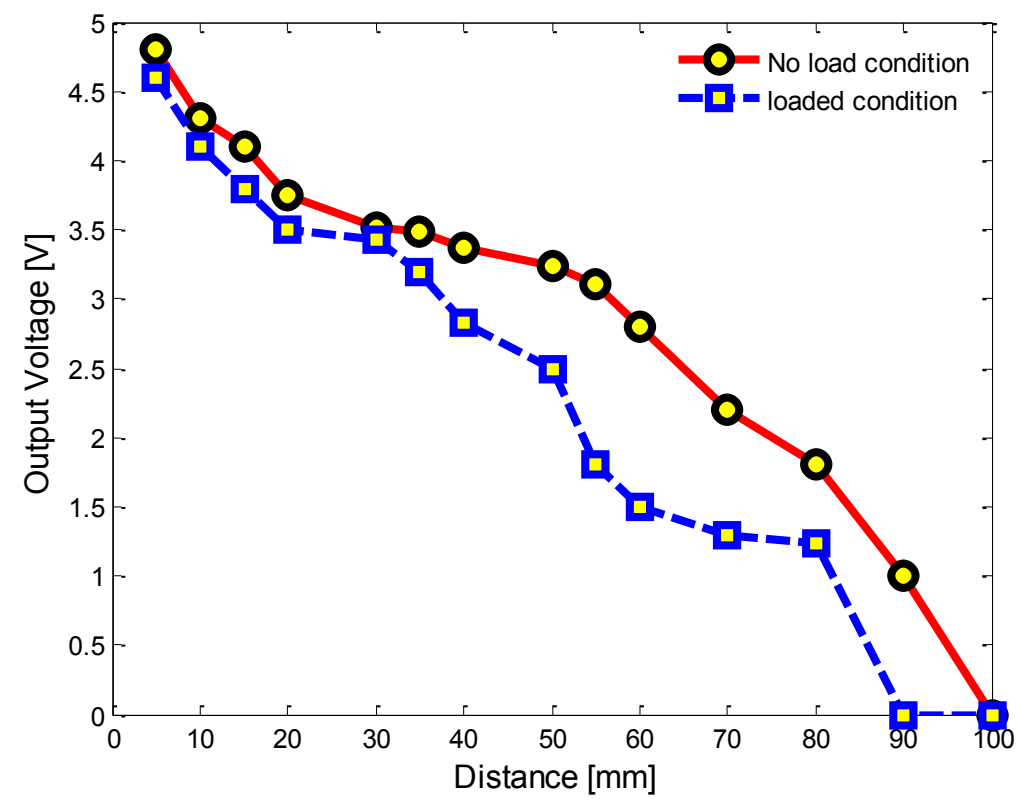

Fig. 8: Measurement of output voltage with respect to coil separation distance.

The first test is carried out to measure the output voltage with respect to the coil separation distance. The transmitter coil is fixed and receiver coil is moved axially apart over a span of $100 \mathrm{~mm}$. The measurement of output voltage at the receiver end as a function of distance is conducted using a meter ruler placed horizontally along the axis of the coils and then the receiver coil is moved in $10 \mathrm{~mm}$ steps axially. Initially when the coil separation is kept at its minimum $(10 \mathrm{~mm})$, the system is able to harvest the maximum voltage of $4.5 \mathrm{~V}$ under loaded condtion and $4.8 \mathrm{~V}$ under no load conditions. Subsequently, the harvested voltage across the load gets decreased gradually as the coil separation distance increases for every $10 \mathrm{~mm}$ of incremental step. Furthermore, it can be observed from results in Fig. 8 that the output voltage with load decreases at a faster rate compared to the output voltage at no load condition for the same coil separation distance. This test is performed by keeping the fixed value of resonant frequency at $130 \mathrm{kHz}$. The optimum coil separation distance is observed to be between $50-60 \mathrm{~mm}$ over a span of $100 \mathrm{~mm}$. The output voltage obtained, at this optimum coil separation distance, is $3.1 \mathrm{~V}$ and $1.8 \mathrm{~V}$ with an efficiency of $62 \%$, and $36 \%$ at the receiver, under no load and loaded conditions respectively as shown in Fig. 8.

$$
\begin{aligned}
& \text { Max. Efficiency }(\text { loaded condition })=(1.8 / 5) \times 100=36 \% . \\
& \text { Max. Efficiency }(\text { No load condition })=(3.1 / 5) \times 100=62 \% .
\end{aligned}
$$

The second experiment is conducted to estimate the power transfer efficiency in terms of voltage ratio under the non-orientated configuration. Here, the coils are not aligned properly as the load coil is placed radially above the source coil with the constant radial 
distance of $10 \mathrm{~mm}$ and applied input voltage of $5 \mathrm{~V}$. Initially, the coils are fixed with the phase angle of 90 degrees, which produces the zero distance between the coils. Subsequently, the receiver coil is moved apart from the source coil in the z-direction with a maximum distance of $70 \mathrm{~mm}$ to measure for effective power transmission. This measurement of output voltage is performed under load and no-load conditions as shown in Fig. 9.

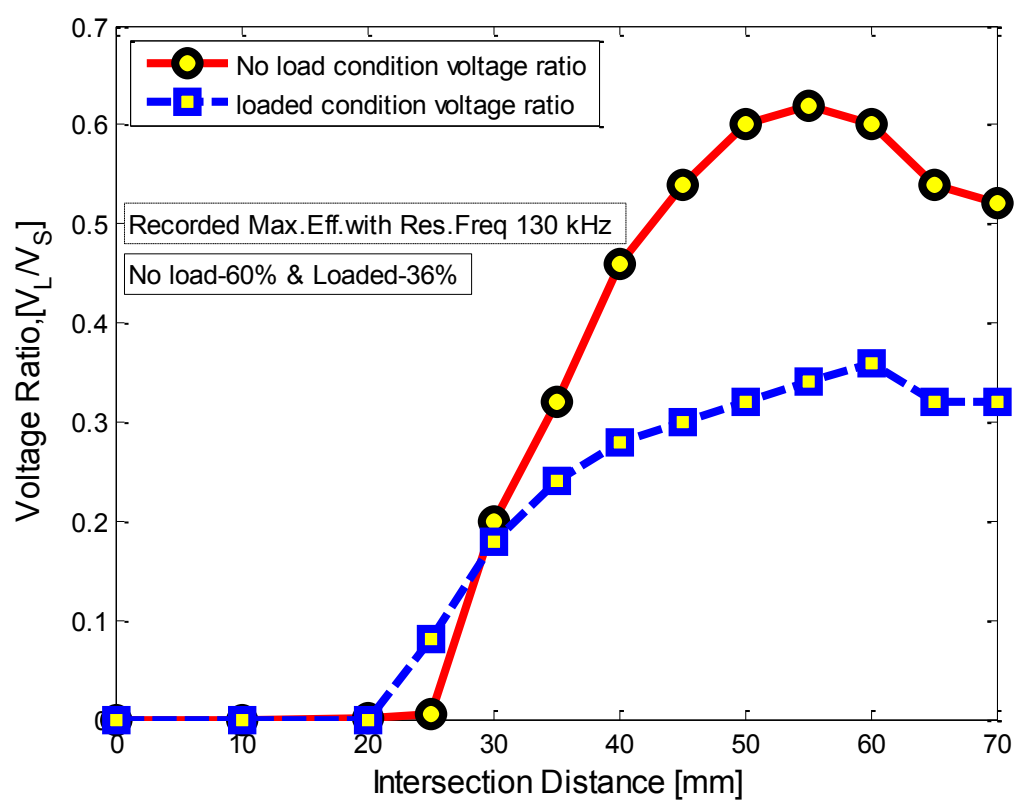

Fig. 9: Measurement of voltage ratio with respect to the distance in axial direction.

It is observed that the voltage ratio is almost zero until a distance of $20-25 \mathrm{~mm}$, which means that the receiver coil is out of phase with the source coil so that no voltage is harvested at the receiver end. Subsequently, the receiver coil is moved axially, which will reduce the phase angle indirectly and hence output voltage is harvested at the receiver end. From the plots shown in Fig. 10, it is observed that the maximum output voltage is achieved at an intersection distance in the range of 50-60 $\mathrm{mm}$ and then gradually decreases as the coil is parted from the source coil, i.e., non-oriented coil configuration.

\section{CONCLUSION}

A newly integrated, password embedded security protection system for WPT application is presented. The design utilizes an Arduino microcontroller for password security implementation. The controller controls the resonant switching frequency of the transmitter coil for effective flux linkage and power transfer between coupled coils. In order to analyze the coupling strength between coils for improving efficiency, two distinct efficiency measurements, as a function of coil separation distance with two coil configurations, are performed experimentally. The wireless power system controlled by digital controller is the unique feature of this work. The performance of the constructed integrated system is effectively demonstrated through the prototype built. The experimental results confirm the effectiveness and good performance of the design, achieving maximum efficiency of $62 \%$ in an ideal case at a distance of $55 \mathrm{~mm}$. The results are in line with those of [16] where power declines beyond critical value of coupling coefficient. 


\section{REFERENCES}

[1] Tesla N. (1914) U.S. Patent 1. 119,732.

[2] Brown WC. (1984) History of Power Transmission by Radio Waves. IEEE Transactions on Microwave Theory and Techniques. MTT-32(9):1230-1242.

[3] Arshad A, Khan S, Zahirul Alam AHM, Tasnim R, Gunawan TS, Ahmad R, Nataraj C. (2016) An Activity Monitoring System for Senior Citizens Living Independently Using Capacitive Sensing Technique. IEEE International Instrumentation and Measurement Technology Conference (I2MTC 2016) Proceedings, 449-454.

[4] Nataraj C, Khan S, Habaebi MH, Abdul Muthalif AG, Arshad A. (2016) Resonant Coils Analysis for Inductively Coupled Wireless Power Transfer Applications. IEEE International Instrumentation and Measurement Technology Conference (I2MTC 2016), 109-114.

[5] Angrisani L, Alessandro GD, Arco MD. (2015) An experimental energy set-up for wireless battery recharging. IEEE International Instrumentation and Measurement Technology Conference (I2MTC 2015) Proceeding, 1699-1704.

[6] Khan IM, Khan S, Khalifa OO. (2012) Transfer of power to low power implanted biomedical devices: Coil design considerations. Proceedings of I2MTC 2012, Graz, Austria.

[7] Torla L, Haider S, Shobaki M, Abdul Muthalif AG, Khan S, Azman A, Mustafah Y. (2013). Low voltage DC power supply with spike-blocking features. I2MTC2013, Minneapolis, 6-9 May 2013.

[8] Sample AP, Meyer A, and Smith JR. (2010) Analysis, experimental results, and range adaption of magnetically coupled resonators for wireless power transfer. IEEE Transactions on Industrial Electronics, 58(2):544-554.

[9] Jabbar H, Jeong YS. (2010) Wirelessly Charging Mobile Devices from Ambient RF Sources. Consumer Electronics (ICCE), 2010 Digest of Technical Papers International Conference, 455-456.

[10] Nataraj C, Khan S, Habaebi MH, Abdul Muthalif AG. (2016) Hybrid of Conical and Spiral Approach for Wireless Power Transfer. IEEE Student Conference on Research and Development (SCOReD 2016), Kuala Lumpur, Malaysia.

[11] Sandrolini L, Reggiani U, Puccetti G, and Neau Y. (2013) Equivalent circuit characterization of resonant magnetic coupling for wireless transmission of electrical energy. International Journal of Circuit Theory Appl., 41:753-771.

[12] Nataraj C, Khan S, Eniola FF, Selvaperumal SK. (2017) Design of Simple DC-to-DC Wireless Power Transfer via Inductive Coupling. International Conference on Advances in Electrical, Electronics, Information, Communication and Bio-Informatics (AEEICB17), Chennai, India.

[13] Xun L, Ng WM, Lee CK, Hui SYR. (2008) Optimal Operation of contactless transformers with resonance in secondary circuits. Proceedings of the Twenty-Third Annual IEEE Applied Power Electronics Conference and Exposition (APEC 2008), Austin, TX, USA, 645-650.

[14] Bright JA, Lee WJ. (1998) Integrated monitoring, protection, and control systems for industrial and commercial power systems. IEEE Computer Applications in Power, 24-30.

[15] Wheeler HA. (1928) Simple Inductance Formulas for Radio Coils. Proceedings of the Institute of Radio Engineer, 16:1398-1400.

[16] Seo D-W, Lee J-H, Lee H-S. (2016) Optimal Coupling to Achieve Maximum Output Power in a WPT System. IEEE Transactions on Power Electronics, 31(6):3994-3998. 